\section{Visita domiciliar no âmbito da Estratégia Saúde da Família: percepções de usuários no Município de Fortaleza, Ceará, Brasil}

\author{
Home visits as a component of the Family Health \\ Program: user's perceptions in Fortaleza, \\ Ceará State, Brazil
}

\author{
${ }^{1}$ Faculdade de Medicina, \\ Universidade Federal do \\ Ceará, Fortaleza, Brasil. \\ Correspondência \\ M. L. M. Bosi \\ Departamento de Saúde \\ Comunitária, Faculdade \\ de Medicina, Universidade \\ Federal do Ceará. \\ Rua Prof. Costa Mendes 1608, \\ 50 andar, Fortaleza, $C E$ \\ 60165-070, Brasil. \\ malubosi@ufc.br
}

\begin{abstract}
Home visits have become increasingly widespread in Brazil since the emergence of the Family Health Program. The present study deals with users' perceptions of these visits, focusing on comprehensiveness and humanization of care. The study was exploratory and qualitative. Twentyone interviews were performed with users from the six administrative health districts of Fortaleza, capital of Ceará State, Brazil. Analysis of the interviews revealed the existence of three core themes: (1) health professional-user relationships, i.e. users' perceptions of completeness and humanization of care during visits; (2) characterization of visits, with emphasis on operational aspects; and (3) user-health facility interaction, focusing on integration with other service. This theme was divided into three items: health facility management, equity, and integration of care. In conclusion, the study suggests that home visiting practices can be improved by enhancing the aspects of intersubjectivity, dialogue, and negotiation between health professionals, users, and the community.
\end{abstract}

Home Visit; Family Health; Health Planning
Adriana Bezerra Brasil de Albuquerque ${ }^{1}$ Maria Lúcia Magalhães Bosi 1

\section{Introdução}

O Programa Saúde da Família (PSF), também denominado Estratégia Saúde da Família, vem desempenhando papel estratégico para a consolidação do Sistema Único de Saúde (SUS), favorecendo a eqüidade e universalidade da assistência por meio de ações inovadoras no setor. Entretanto, não se pode admitir, tomando como base apenas a expansão, que dimensões de qualidade, tais como: integralidade das ações, humanização e satisfação das demandas dos usuários, encontram-se plenamente contempladas na referida estratégia.

O Programa de Agentes Comunitários de Saúde (PACS) teve início, no Brasil, em junho de 1991, sendo, portanto, precursor do PSF. Em janeiro de 1994, formaram-se as primeiras equipes do PSF compostas por médicos, enfermeiros e agentes comunitários de saúde, tendo sido o Ceará o primeiro estado a implantar o PSF e o PACS. No Município de Fortaleza, espaço deste estudo, a implantação se deu alguns anos mais tarde, mais precisamente em 1999, e vem em constante processo de expansão representando, na atualidade, um nó crítico para a gestão da atenção básica. Torna-se portanto, estratégico avaliar, neste estágio, o componente visita domiciliar, cujo significado se amplia passando a ser concebida como parte de um processo de atenção continuada e multidisciplinar, no qual se realizam práticas sa- 
nitárias, assistenciais e sociais, perpassadas pelo olhar da integralidade 1 .

O PSF pressupõe a visita domiciliar como tecnologia de interação no cuidado à saúde ${ }^{2}$, sendo um instrumento de intervenção fundamental utilizado pelas equipes de saúde como meio de inserção e de conhecimento da realidade de vida da população, favorecendo o estabelecimento de vínculos com a mesma e a compreensão de aspectos importantes da dinâmica das relações familiares 3,4 .

$\mathrm{A}$ atenção às famílias e à comunidade é o objetivo central da visita domiciliar, sendo entendidas, família e comunidade, como entidades influenciadoras no processo de adoecer dos indivíduos, os quais são regidos pelas relações que estabelecem nos contextos em que estão inseridos. Compreender o contexto de vida dos usuários dos serviços de saúde e suas relações familiares deve visar ao impacto nas formas de atuação dos profissionais, permitindo novas demarcações conceituais e, conseqüentemente, o planejamento das ações considerando o modo de vida e os recursos de que as famílias dispõem 2,4 .

No que tange à articulação com o modelo assistencial, o discurso relativo à integralidade e à humanização do cuidado assume papel de destaque na reorientação do SUS. A relevância da visita nesse processo evidencia-se pelo fato de essa dispor de condições propícias a mudanças, confrontando o modelo hegemônico, centrado na doença, no qual predomina uma postura profissional de indiferença e de pouca interação com os usuários. A superação desse modelo requer dos profissionais de saúde a construção de um pensar e um fazer sustentados na produção social do processo saúde-doença 5 .

Com a criação do SUS, a integralidade surge como um dos principais pilares na construção da Atenção Primária à Saúde, uma vez que se fundamenta na articulação das ações de promoção, prevenção e recuperação, além da abordagem integral dos indivíduos e familiares 6 . Desenvolve-se, desde então, uma reflexão sobre a integralidade que identifica três grandes conjuntos de sentidos usualmente empregados, os quais remetem a: uma nova atitude por parte dos profissionais de saúde; uma crítica à dissociação entre práticas de saúde pública e práticas assistenciais; uma recusa em objetivar e recortar os sujeitos sobre os quais as ações incidem 7. Tais premissas implicam, acima de tudo, uma recusa ao reducionismo e à objetivação dos sujeitos, bem como a afirmação de uma abertura ao diálogo de modo a promover "um exercício de seleção negociada do que é relevante para a construção de um projeto de intervenção" 8 (p. 1415).
O caráter polissêmico do termo integralidade sustenta que essa é uma ação social resultante da permanente interação dos atores na relação demanda e oferta, considerando aspectos subjetivos e objetivos, nos planos individual e sistêmico 9. A relevância da integralidade na reorientação do modelo assistencial reside justamente no fato de ser esse, dentre os princípios do SUS, "aquele que confronta incisivamente racionalidades hegemônicas no sistema”, contrapondose a uma visão reducionista e fragmentada dos indivíduos 10 .

No que tange ao conceito humanização, torna-se necessário demarcar, de forma clara, o entendimento do que seja esse humanizar, que consoante certas proposições "se distancia tanto das doutrinas humanistas quanto do humanitarismo em um sentido filantrópico" 11 (p. 99). Nesse sentido, as mesmas autoras afirmam que "humano se refere (...) ao plano das relações intersubjetivas que se processam nas práticas sociais (...) tendo como seu fundamento a capacidade de simbolização e construção de sentidos em relação" 11 (p. 99). Cabe ressaltar, ainda, que relações subjetivas são aqui concebidas como trocas simbólicas entre sujeitos historicamente situados, o humano se constituindo em relação e não existindo fora dessa intersubjetividade 11 .

Diante do exposto e considerando a relevância da visita domiciliar, concebida como tecnologia de interação potencialmente capaz de contribuir, no âmbito de PSF, para uma nova proposta de atendimento integral e humanizado, este estudo buscou compreender, em um grande município do Nordeste do Brasil, a perspectiva dos usuários acerca desse componente assistencial, privilegiando, na análise, as dimensões humanização e integralidade do cuidado.

\section{Metodologia}

Para compreender esse fenômeno sob a ótica dos usuários, o estudo se fundamentou na metodologia qualitativa de investigação social, na vertente crítico-interpretativa. Tal opção metodológica deve-se ao fato de o objeto, por sua natureza, não admitir respostas numéricas, expressas em proporções, freqüências de distribuição e outros recursos da quantificação ${ }^{12}$. A investigação qualitativa representa um modo rigoroso de exploração de questões nas ciências humanas e sociais, sendo o conhecimento obtido uma síntese que emerge da dialética entre sujeito epistêmico e fenômeno estudado 13 .

No âmbito de um estudo que toma por objeto percepções humanas sobre um dado fenômeno, cabe esclarecer como esse termo/conceito 
é aqui demarcado. Dentre os distintos sentidos a ele conferidos, adotamos a vertente que entende a percepção como uma síntese subjetiva advinda dos estímulos sensoriais e das experiências, unindo, portanto, estímulos objetivos e interpretações subjetivas. Tal posicionamento se distancia do realismo ingênuo, vertente que sustenta a possibilidade de uma apreensão direta e precisa de um "mundo exterior", com base nos sentidos.

O fundamento epistemológico adotado na investigação foi o enfoque hermenêutico-crítico, vertente que visa a desvelar o que faz sentido para o sujeito, tal como percebido por ele e manifesto, confrontando essa produção subjetiva com a materialidade a que a mesma dialeticamente se vincula 14 .

Nessa tradição, não se confere relevo à representatividade estatística, uma vez que a estratégia para seleção da "amostra" utilizada não foi a probabilística, e sim a teórica ou intencional (theoretical strategy) 15,16. Dessa forma, a seleção dos informantes se deve à sua relevância ante o objeto investigado, ou seja, ao acúmulo subjetivo ante os fenômenos a serem compreendidos. Dessa forma, a generalização não mais se orienta pelo referencial estatístico, validando-se, assim, por critérios internos à epistemologia qualitativa que visam à compreensão de processos, não podendo, portanto, derivar de cálculos que definem, $a$ priori, o tamanho amostral ideal.

Com base nessas premissas, para a seleção dos usuários, realizou-se um levantamento inicial do total de equipes completas no município. Das 72 equipes existentes, apenas 46 eram compostas por médico, enfermeiro e agente de saúde. Dentre essas, escolhemos, aleatoriamente, dez equipes, mantendo a preocupação de selecionar uma equipe de cada uma das seis regionais. Apenas na regional III, escolhemos duas equipes por essa apresentar maior número de unidades básicas de saúde da família.

A seleção da amostra teve como critérios: ter sido visitado, no mínimo, duas vezes pelo médico ou enfermeiro e também pelo agente de saúde; estar inserido no serviço por um período de tempo que tornasse possível reconhecer algum membro da equipe; estar em condições físicas e psicológicas de responder à entrevista, além de concordar livremente em participar.

Para a localização dos possíveis informantes, obtiveram-se os nomes dos usuários por meio do levantamento dos cadastros, bem como dos registros e fichas de "contingência", ou seja, fichas manualmente preenchidas no momento da visita contendo informações do estado de saúde do usuário e, logo após, registradas nos arquivos do sistema informatizado da unidade de saúde.
Não foi considerada a data da última visita como critério para participação na pesquisa, mas, sim, ter recebido visita por, no mínimo, um dos membros da equipe. A amostra final foi constituída por 21 usuários.

Na seleção da técnica para obtenção das informações, a escolha recaiu sobre a entrevista individual, apoiada em um eixo flexível, buscando um procedimento não diretivo, de modo a permitir um diálogo mais profundo e rico, acerca do fenômeno focalizado 17 .

As entrevistas, com duração média de 40 minutos, foram previamente agendadas pelo agente de saúde e por uma das pesquisadoras no próprio domicílio, sendo essa a responsável pela realização das mesmas. No processo, identificamos elementos significativos para a exploração das dimensões inerentes ao objeto, sobretudo a integralidade e humanização do cuidado, a partir da compreensão dos significados e experiências da relação equipe - usuários, tendo como um dos eixos orientadores, na etapa de análise do material, o discurso do SUS e seus princípios.

Os procedimentos da pesquisa garantiram o anonimato dos usuários e profissionais da saúde. Para tanto, nas narrativas textuais apresentadas neste trabalho, excluíram-se os nomes dos entrevistados, e a identificação de cada um deles se fez apenas pela letra alfabética, acrescida da numeração correspondente a cada entrevistado. Quanto aos profissionais citados pelos informantes, utilizamos a letra $\mathrm{P}$, acrescida da inicial da formação do profissional da equipe (p.ex.: $M$ - médico, E - enfermeiro e A - agente de saúde), para denominá-los nas narrativas.

Todas as entrevistas foram gravadas com o consentimento dos entrevistados. Após a transcrição das entrevistas, deu-se o processamento, a categorização e, posteriormente, a interpretação das informações. A fase interpretativa, na qual se articulou o referencial teórico com as narrativas, correspondeu ao exercício hermenêutico pretendido, desvelando sentidos cuja compreensão demandou a mediação de conceitos ou categorias analíticas demarcadas no quadro teórico, já que, na perspectiva aqui adotada, a compreensão não se dá de forma imediata.

Na Tabela 1, demonstramos os principais eixos derivados da categorização, bem como a rede interpretativa dela resultante.

Delineamos o processo de categorização iniciando com a identificação das temáticas presentes no discurso de cada informante, ou seja, focalizando cada depoimento no que concerne à sua estrutura e singularidade. Na seqüência, realizamos a leitura "horizontal" do material, verificando suas confluências e divergências, com objetivo de identificar os eixos comuns que 
Temas centrais

Aspectos relacionais da visita

Percepção da relação profissional usuário

Humanização do cuidado

O sentido da integralidade
Característica da visita

Freqüência e duração

Seleção dos atendimentos
Vinculação com o serviço

Funcionamento da unidade

Eqüidade

Integração da atenção desvelassem a estrutura, iluminando eventuais traços dissonantes que foram, da mesma forma, valorizados no exercício hermenêutico.

Tal movimento realizado, conforme já aludido, com a mediação das categorias analíticas levou à sistematização das informações em temas e dimensões, configurando a construção do que aqui denominamos "rede interpretativa" que, para além de um recurso de exposição, pretende expressar o entrelaçamento entre os eixos, temas e dimensões.

Essa rede se estruturou tendo, como eixo, três temáticas ou temas centrais que emergiram após várias leituras e releituras das falas dos sujeitos. São elas: (1) Aspectos Relacionais da Visita; (2) Características da Visita; (3) Vinculação com os Serviços.

\section{Análise e discussão}

No primeiro tema, abordaremos percepções dos usuários quanto aos aspectos relacionados com a humanização do cuidado e com a integralidade da assistência na visita domiciliar, objeto propriamente dito deste estudo. Nesse tema, emerge a subjetividade inerente ao processo de vivência e interação entre usuários e profissionais da equipe.

Já o segundo, Características da Visita, focaliza percepções acerca de prioridades, bem como de aspectos operacionais da mesma. No terceiro e último tema, focalizamos questões relacionadas com os serviços (unidades) de saúde, enfocando aspectos operacionais, bem como de eqüidade $\mathrm{e}$ de integração entre os serviços.

\section{Aspectos relacionais da visita}

A primeira dimensão do primeiro tema - percepção da relação profissional-usuário - se expressa em múltiplos significados revelados nos depoimentos dos sujeitos. Nas falas, emergem palavras que traduzem sentimentos favoráveis à natureza da ação, tais como: felicidade, esperança, costume.

"É bom, porque quando (a equipe) vem, a gente tem aquela esperança que aquela pessoa vai passar algum remédio, vai dar algum conforto, né?" (E5).

Para alguns informantes, evidencia-se claramente a necessidade de "estar acostumado" com o profissional para que a relação aconteça: “(...) os outros são bons, mas é diferente. A gente não é acostumada, (...) com eles, a gente vê pela primeira vez, é muito difícil ver, é meio estranho, a gente fica meio acanhada, é muito diferente; aqui com eles já estou acostumada" (E8).

O excerto acima confirma a empatia e o vínculo como elementos centrais na relação de cuidado. No aspecto da comunicação profissionalpaciente, devem existir dois sujeitos em relação de troca e alternância de falas, sendo necessária uma sintonia entre ambos 18 .

Em contrapartida, para outros, a dificuldade de diálogo e a falta de comunicação são tão evidentes que se constrói uma espécie de "abismo” entre usuário e profissional. Nesses casos, manter um simples diálogo, dizer o que sente, parece ser algo tão difícil que, em certos casos, chega a causar uma paralisia na comunicação. Atribuímos essa paralisia à questão da relação profissional-usuário mostrar-se distanciada e sem vinculação.

"Eu não tenho relação com eles, eles vêm, perguntam alguma coisa, e eu respondo e pronto; só isso mesmo" (E1).

Tais questões relacionais se capilarizam na segunda dimensão - humanização do cuidado.

Heidegger 19, em sua famosa obra "Ser e Tempo", afirma que o cuidado se encontra, antes de tudo, na raiz do ser humano. E o fazer humano sempre vem impregnado de cuidado como um "modo-de-ser" essencial 20.

Nessa perspectiva, cabe observar que cuidar é: “mais que um ato, é uma atitude. Portanto, abrange mais que um momento de atenção, de zelo e de desvelo. Representa uma atitude de ocu- 
pação, preocupação, responsabilização e de envolvimento afetivo com o outro" 21 (p. 33).

$\mathrm{Na}$ fala exposta a seguir, evidencia-se a percepção do cuidado, em um dos seus sentidos: significativo apoio à minimização da solidão e do sofrimento vivenciado no entorno familiar. Nesse caso, o profissional da equipe de saúde da família assume, na perspectiva do usuário, o lugar de membro da família.

“(...) A família que eu tenho são meus médicos, porque é com quem eu converso e com quem (...) realmente (...) eu encontrei apoio, mais de que na minha família. Eu sou mais cuidada por eles do que pela minha família. Eu me sinto bem no dia em que eles vêm... eles conversam comigo. Por isso que, às vezes, eu digo que a família que eu tenho são eles, e eles disseram que, enquanto eu não morrer, eles estão me dando força (...) é a família que eu tenho" (E1, grifos nossos).

Na impossibilidade de explorar, neste espaço, os aspectos sócio-históricos subjacentes a esse "lugar na família" concedido aos profissionais de saúde, cabe, ao menos, mencionar, a vulnerabilidade social que marca o cotidiano de muitos usuários da rede pública, sobretudo, quando enfermos.

Nas práticas de saúde, do ponto de vista dos usuários, não raro, constata-se o humanizar como o "bom humano" - pessoa boa, de bom coração. Em ambas as percepções, o humano é dotado de valorização e amor ao próximo, sem discriminação do contexto e da classe social.

“(...) Quem dá valor a outra pessoa. Eu acho uma gratidão profunda a pessoa amar a Deus e amar ao próximo, como se dissesse eu sou pobre e você é rico. Ele atende, da maneira que atende você, ele atende a mim" (E20).

Observamos, ainda, que, para muitos entrevistados, "educação" vincula-se com humanização para designar o sujeito portador de "atitudes humanas", desvelando uma distância entre o discurso do SUS e essas percepções. Para os entrevistados, "pessoas educadas" - gentis e atenciosas no modo de tratar o outro - são mais humanas e têm o "coração melhor" que o das demais pessoas. Isso brilha nas falas como sinônimo de humanização. O excerto abaixo ilustra a percepção coletiva dos informantes.

"Quem tem educação (...) tem bom coração (...) gente que não tem educação e nem tem coração, é desumana. É importante a pessoa ser humana, tratar o outro bem, porque a gente fica gostando (...) fica querendo bem. A gente diz que é bem educado (...)" (E10).

Finalizando os comentários relativos aos aspectos relacionais da visita, iremos discorrer sobre a integralidade, como última dimensão desse primeiro eixo. Nessa dimensão, buscamos anali- sar os sentidos e usos atribuídos à integralidade como princípio norteador do SUS, fundamental na organização dos serviços e práticas de saúde, conforme já antes discutido.

Um primeiro sentido da integralidade prima por atendimento profissional 21. O usuário, quando percebe que o atendimento ofertado não correspondeu às suas expectativas, tem uma sensação de desagrado por não ter sido compreendido e respeitado. Tal circunstância, não raro, conforme assinalado por outros autores, resulta na busca por um novo atendimento que, se por um lado, pode multiplicar o atendimento, por outro lado, é capaz de reverter a sensação de insatisfação 7. Para um dos nossos informantes, o aborrecimento decorrente de um atendimento recebido foi substituído, em outra oportunidade, por satisfação de suas demandas, fundada em uma relação de reciprocidade: "Na vez que consultei com o Doutor, não gostei muito dele não. Ele mandou eu dizer o nome dos meus medicamentos, eu disse o nome e falei que precisava de outro porque estava com gastrite. Foi aí que ele passou o remédio caríssimo... Como eu tenho IPEC (Instituto de Previdência Médica do Estado do Ceará), fui a outro médico, e ele me consultou bem direitinho. Na segunda vez, fui muito bem atendida" (E20).

A atitude médica na visita também é percebida como resposta à existência do outro, compreendida como uma totalidade e não reduzida à dimensão exclusivamente biológica: "Não é necessário eu ir para o posto porque eu estou bem, não estou sentindo nada, nem minha filha. Mas se ela (PE) passa nessa rua, ela chega a mim (...) Está entendendo? Vem até aqui! Não é para consultar não, simplesmente para uma visita" (E13).

Para outros informantes, a relevância do atendimento compreende a resolução da sua queixa biológica, deixando claro o valor simbólico conferido ao medicamento.

"Gosto porque ele atende a gente bem, ele resolve os problemas, ele passa remédio. Da outra vez, eu estava com dor, e ele passou logo a receita para eu pegar meus remédios" (E15).

No segundo e terceiro conjunto de sentidos, a integralidade é demarcada, respectivamente, como modo de organizar as práticas de saúde e com as políticas especiais desenhadas para dar respostas a um problema que aflige o indivíduo ou a coletividade 7 .

Na organização do processo de trabalho, a integralidade articula atenção à demanda espontânea com a oferta programada de atenção à saúde, buscando ampliar as possibilidades de apreensão e satisfação das necessidades individuais ou de um grupo populacional.

“(...) Facilita porque só em não ir até lá, porque ela não pode andar, tem que botar e levar num 
carro, ai é o maior sacrifício para levar, essa visita é uma grande ajuda. Só em vir aqui, examinar ela, tirar a pressão dela (...) facilita demais, eu gosto!" (E11).

A integralidade como acesso às técnicas de diagnóstico e ao tratamento necessário a cada caso permite articular a atenção básica aos meios de diagnóstico e atenção especializada, quando necessário.

“(...) Facilitaram. Já fiz ultra-som e muitos exames que eu faço. Toda vida que precisei, graças a Deus, consegui" (E11).

Em alguns casos, os informantes não usufruíram desse privilégio e sentem prejudicadas suas necessidades em virtude da deficiente organização do serviço.

"Preciso fazer o exame da esteira. Estou esperando até hoje. Em junho deste ano, vai fazer um ano que eu espero" (E5).

O último sentido de integralidade relacionase às "políticas específicas", desenhadas para dar respostas a determinados problemas de saúde ou problemas que atingem um grupo populacional 7 .

Quanto a isso, foi interessante observar que alguns entrevistados percebem modificações do sistema atual se comparado com as ações políticas que o antecederam. Para alguns deles, as experiências vivenciadas em outras épocas demonstram sua satisfação com o serviço ora oferecido.

"Para mim, é uma satisfação muito grande, porque, se eu fosse me tratar mesmo pelo INPS (Instituto Nacional de Previdência Social), eu já tinha batido as botas há muito tempo, viu? Agora eles me dão ajuda, remédio e tudo e, graças a Deus, até hoje. O INPS sabe como era, não?" (E7).

\section{Características da visita}

O segundo tema da rede interpretativa aborda aspectos da visita domiciliar, evidenciados nos relatos dos informantes e as características provenientes da sua realização. Dessa temática, desdobraram-se duas dimensões: a primeira delas, freqüência e duração, tem, como foco, as percepções dos entrevistados quanto à freqüência das visitas e ao tempo dispensado pelos profissionais na realização das mesmas. Apesar de ser uma atividade programada e constar nos cronogramas das equipes, as visitas demoram a acontecer.

"Ele (PM) é muito difícil vir aqui em casa, muito. Quem vem maisé (PA) que vai buscar meus remédios (...) ele vem aqui de vez em quando. Só ele" (E2).

Para os usuários, a ida dos profissionais ao domicílio é algo muito esporádico e com duração muito reduzida. Para alguns entrevistados, os profissionais são impossibilitados de demorar nos domicílios devido a vários motivos, dentre eles, a grande demanda de usuários que necessitam da visita, demonstrando uma dimensão de operacionalização ainda problemática:

“A senhora sabe, né? É tudo correndo. Não pode perder muito tempo. Quando eles demoram, perguntam as coisas que é para fazer, conversa com a gente e vão embora. Não pode demorar muito não (...) Quando eles vêm, com a missão de atender não sei quantos" (E19).

Quanto à seleção dos atendimentos, focalizamos, na perspectiva dos entrevistados, os motivos pelos quais eles recebem a visita dos profissionais em seus domicílios. Para alguns entrevistados, o que transparece é que as pessoas que recebem a visita da equipe do PSF são aquelas que não possuem condições de se dirigir à unidade de saúde para receber atendimento médico, quer seja por limitações físicas ou agravos instalados.

“Acho que é por causa do paciente, não é não? Que não pode se locomover e fica sendo bem cuidado pelo posto" (E20).

Alguns entrevistados acreditam que os profissionais visitam os usuários em seus domicílios por obrigação ou determinação do próprio serviço.

"Não sei se é obrigação dele porque eu estou assim, né? Sem poder andar. (...) ele (PE) não visita somente eu. Tem outras velhinhas por aí que ele visita. Que estão doentes" (E17)

Diferentemente desses, existem outros entrevistados que relacionam essa atitude à bondade e presteza do profissional para com o usuário do serviço.

"É porque eles acham que é muito dispendioso para mim, né? Por isso, eles vêm aqui. Isso aí é bondade, não é outra coisa não viu? Mas eles vêm porque querem vir mesmo" (E19).

De qualquer forma, no material discursivo, sobressaem a pouca clareza quanto à natureza $\mathrm{e}$ aos propósitos desse componente no interior da Estratégia Saúde da Família e o lugar do usuário como cidadão.

\section{Vinculação com o serviço}

Retratamos, nesta terceira e última temática, percepções dos usuários sobre o funcionamento do serviço. Embora refletindo a influência do paradigma tradicional, ainda predominante, o discurso dos entrevistados sinaliza diretrizes que abordam eqüidade, integralidade, inserindo o acolhimento, a escuta e assistência na interface com os serviços.

A dimensão funcionamento da unidade enfoca procedimentos referidos a aspectos que apontam dificuldades intrínsecas e extrínsecas 
aos serviços. Expandir o PSF em grandes centros urbanos tem sido uma tarefa difícil para o Ministério da Saúde, mantendo-se a expectativa de que o Programa possa reestruturar a atenção básica em centros urbanos mais desenvolvidos. Contudo, alguns fatores dificultam a implementação do PSF nas grandes cidades, tais como: falta de financiamento, qualificação insuficiente dos profissionais, formato padrão das equipes sem respeitar as particularidades locais, insuficiente relação do PSF com outros serviços, redes ambulatoriais e hospitalares, dinâmica urbana complexa, além de violência urbana, tráfico de drogas e armas, e dificuldade de incorporação de novos saberes e práticas nas ações coletivas 22,23,24.

Alguns entrevistados, quando questionados sobre a diferenciação do atendimento na unidade e no domicílio, relatam a preferência pela assistência domiciliar por essa possibilitar uma maior vinculação com os profissionais. Apesar de o tempo destinado à visita, conforme vimos no tema anterior, ser limitado, o seu aproveitamento se acentua tendo em vista o favorecimento do diálogo, aspecto que, pelo que constatamos, re-significa a percepção da dimensão temporal: "Não, aqui é melhor porque a gente conversa é muito, né? Lá não pode conversar porque é muita gente. Não pode dar atenção, e ela vindo aqui a gente conversa, eu digo as coisas que eu estou sentindo bem direitinho! Mas lá eu vou tomar o tempo dela todinho, conversando e tudo, não posso, porque tem muito paciente!" (E11).

Contudo, cabe ressaltar que, para outros usuários entrevistados, não há diferenciação entre os atendimentos ofertados nos dois lugares. Alguns ainda preferem o atendimento na própria unidade de saúde. Assim, cabe retomar a já aludida polarização das percepções relativas à ausência/ presença de vínculo, aspecto que não nos autoriza a falar de uma homogeneidade no plano das experiências com a visita domiciliar.

Na dimensão seguinte, aqui denominada eqüidade, esse princípio emerge como uma questão central nos serviços de saúde, ainda que de forma, por vezes, velada, mas que as categorias analíticas permitiram iluminar. Embora não seja uma novidade conceitual, a eqüidade é recente como princípio orientador do SUS. Há um panorama de conceitos de igualdade e eqüidade na proposta da Reforma Sanitária na qual a direcionalidade das políticas de saúde para a redução das desigualdades sociais e melhoria da qualidade de vida dos mais necessitados consta como prioridade 25.

Para alguns entrevistados, o fato de ele e seus familiares receberem assistência domiciliar lhes dá a certeza de serem bem atendidos. Poder usu- fruir a visita da equipe em seu domicílio revela a complexidade resolutiva inerente às propostas da ESF que é atender indistintamente e igualitariamente todos que necessitam do serviço.

"Aqui eles vêm saber se está todo mundo com saúde. É uma necessidade que eu tenho" (E13).

Para outros, o atendimento estabelecelimites. Isto é, somente o paciente cadastrado para visita é quem recebe atenção por parte dos profissionais que realizam o atendimento. O profissional vai embora logo e não investiga se tem mais alguém precisando de atendimento: "Eles não perguntam se tem mais alguém da família precisando de algum atendimento. Minha irmã é quem está sempre presente na consulta, mas não fala nada dos problemas que tem dentro de casa" (E10).

Os aspectos que aparecem na última dimensão - integração da atenção - relacionam-se com a migração do usuário para outros níveis de atenção dentro do sistema do serviço de saúde, conforme as necessidades e a complexidade do seu tratamento. No âmbito da rede de serviços, observamos a peregrinação de pessoas em busca de resolver suas necessidades e se livrarem dos "fenômenos" (orgânicos ou emocionais) que as afligem. Neste estudo, uma usuária descreve esse tipo de vivência: "Eu sinto uma dor terrível nos meus ossos. Eu já me consultei em vários locais. Aqui mesmo, mas, não encontrei remédio para isso não. O que eu desejava era resolver isso. Encontrar um meio para resolver este problema (...) mas não tem, não existe (...)" (E6).

Reiteramos aqui uma indagação: por que será que as pessoas continuam buscando várias instituições, inclusive emergências, para resolver seus problemas de saúde? Trata-se de uma discussão muito ampla que não intencionamos aqui esgotar. Contudo, um dos fatores contribuintes é, sem dúvida, a insatisfação com o atendimento, bem como a ausência de acolhimento nos serviços, aspectos que impedem que a referência se paute em parâmetros confiáveis.

Para alguns informantes, o recurso mais utilizado para atender suas necessidades quando adoeciam era a ligação telefônica para os serviços de ambulância, pois esses realizavam o primeiro atendimento, até serem levados ao hospital. Para um deles, a melhor opção era ser atendido na instituição hospitalar. "A preferência individual das pessoas pelo atendimento hospitalar faz parte da história passada e presente das políticas de saúde no país, que tem no itinerário da busca da população pela cura a representação de que o hospital é o lugar que reúne todas as possibilidades de solucionar seu problema de saúde" 9 (p. 72). Tal assertiva ressoa nesta fala: "Quando estamos doentes ou qualquer coisa, telefonamos e vem a ambulância. Hoje em dia é (um serviço) muito bom" (E19). 
O PSF e a visita domiciliar como uns dos seus componentes assumem, portanto, uma dimensão política e assistencial de promoção em saúde que interfere na lógica da oferta e da demanda, pela qual a integração da atenção, a satisfação do usuário, bem como a democratização e a politização de conhecimentos relacionados ao processo saúde e doença, ao que parece, atuam de maneira concreta na organização e produção dos serviços de saúde.

\section{Considerações finais}

Ao final deste estudo, não temos a pretensão de apontar posições absolutas ou estanques acerca do fenômeno investigado, mesmo porque, além da diversidade retratada por meio da vertente metodológica aqui adotada, o processo de conhecimento, por ser processo, não admite ponto de chegada. Dialeticamente, recomeça em novo plano no momento em que o ciclo anterior se finaliza.

Ao longo deste estudo, evidenciou-se que, para alguns usuários, a visita domiciliar facilitou suas vidas. O que antes parecia difícil e penoso, agora, com a visita da equipe, é percebido como via para a garantia de direitos, além de facilitar o acesso a técnicas de diagnóstico e tratamento. Para outros, contudo, as dificuldades persistem, não sendo percebidas melhorias, já que a organização do serviço e a assistência profissional são avaliadas como ainda deficientes, uma vez que revela um não compromisso com a alteridade e com o resgate do continuum saúde-doença.

A falha na comunicação entre usuários e profissionais, bastante enfatizada neste estudo, embora já se evidenciem depoimentos dissonantes, demonstra dificuldades de os usuários serem integralmente reconhecidos, bem como terem suas demandas escutadas e atendidas nesse espaço. A assistência à saúde demanda, portanto, um modo diferenciado de estar a serviço do usuário.

Ao nos aproximarmos, neste estudo, da subjetividade dos usuários, constatamos a percepção do cuidado significando minimização da solidão e do sofrimento. Como vimos, o discurso da humanização, para os usuários informantes deste estudo, é que humano é aquele sujeito dotado de amor ao próximo, que trata o outro com delicadeza e respeito. À parte o debate conceitual em curso sobre esse complexo conceito, tal sentido, ao lado de outros, merece ser considerado na demarcação de práticas pautadas na humanização.

Cabe ressaltar que o cuidado não implica em rejeição da técnica, mas em reinventar o modo de intervenção tecnicista sobre a doença (ou en- fermidade), no qual ainda se confere prioridade aos rótulos ou diagnósticos, à desqualificação da dor e ao ajustamento da pessoa às instituições e suas práticas.

Atualmente, nos novos espaços, integralidade implica, dentre outros aspectos, a busca de atitudes profissionais que correspondam às expectativas e necessidades dos usuários, já que a satisfação dos usuários é, em si, resultado da assistência em saúde. Neste ponto, destacamos o deslizamento entre os pólos objetivo e subjetivo expressos na diversidade e mesmo nas divergências de sentimentos presentes na produção subjetiva dos usuários que engloba desde a resolução da sua queixa biológica até conquistas em termos de liberdade e autonomia.

Apesar de ser uma atividade programada e inserida no cronograma de atividades, a visita domiciliar é ainda percebida, pelos usuários, como algo esporádico, quando realizada. Contudo, alguns profissionais apesar de exercerem essa atividade em tempos reduzidos, contemplam, em muitas ocasiões, sentimentos de inquietude dos usuários, favorecendo uma vinculação mais efetiva profissional-usuário do que aquela que ocorre nas unidades de saúde.

Em síntese, parece-nos evidente a idéia de que o cuidado domiciliário decorrente da Estratégia Saúde da Família engloba e perpassa modalidades de atenção que visualizam características fundamentais para a garantia da integralidade, da intersubjetividade inerente à humanização e ao cuidado centrado no usuário e sua família.

Reverter o modelo de assistência ainda hegemônico implica buscar uma assistência integral, equânime e que garanta a qualidade de vida e a autonomia dos sujeitos do processo. Implica, também, assumir o cuidado domiciliário como uma interface de diálogo entre profissionais de saúde, o indivíduo sob cuidado e sua família, modelo no qual há que se valorizar a subjetividade com criação de vínculo e co-responsabilização dos sujeitos, bem como a ativação de redes sociais voltadas à produção do cuidado em saúde, nos vários contextos. 


\section{Resumo}

A visita domiciliar vem ganhando força nesta última década, com o advento da Estratégia Saúde da Família. O presente estudo tem como objetivo compreender percepções de usuários acerca da visita domiciliar, demarcando, como dimensões analíticas, a humanização e a integralidade do cuidado. Trata-se de um estudo de natureza qualitativa, fundamentado na vertente crítico-interpretativa. Realizaram-se 21 entrevistas em profundidade com usuários que residiam nas áreas pertencentes às seis Secretarias Executivas Regionais de Saúde do Município de Fortaleza, Ceará, Brasil. A análise evidenciou três eixos ou temas centrais: (1) aspectos relacionais da visita domiciliar (2) características operacionais da visita e (3) integração da atenção com outros niveis de complexidade, desdobrando-se cada um dos três temas em distintas dimensões. Os resultados deste estudo reiteram a importância da assistência domiciliar, bem como sinalizam o lugar da dimensão subjetiva, uma vez que o sucesso das práticas em saúde depende não apenas do componente técnico, mas de outras tecnologias baseadas na aproximação, diálogo e vinculação entre profissionais, usuários e serviços.

Visita Domiciliar; Saúde da Família; Planejamento em Saúde

\section{Colaboradores}

A. B. B. Albuquerque e M. L. M. Bosi participaram da concepção do estudo, da construção do modelo analítico e da interpretação do material obtido. A primeira autora desenvolveu o trabalho de campo, sob orientação da segunda, junto ao Programa de Mestrado em Saúde Pública, Universidade Federal do Ceará.

\section{Referências}

1. Savassi LCM, Dias MF. Visita domiciliar. Grupos de estudo em saúde da família. http://www.smmfc. org.br/gesf/gesfvd.htm (acesso em 02/Abr/2008).

2. Sakata KN, Almeida MCP, Alvarenga AM, Craco PF, Pereira MJB. Concepções da equipe de saúde da família sobre as visitas domiciliares. Rev Bras Enferm 2007; 6:659-64.

3. Giacomozzi CM, Lacerda MR. A prática da assistência domiciliar dos profissionais da estratégia de saúde da família. Texto \& Contexto Enferm 2006; 4:645-53.

4. Takahashi RF, Oliveira MAC. A visita domiciliária no contexto da saúde da família. http://ids-saude. uol.com.br/psf/enfermagem/tema1/texto8_1.asp (acessado em 15/Abr/2008).
5. Ayres JRCM. Cuidado: tecnologia ou sabedoria prática? Interface Comun Saúde Educ 2000; 6:117-20.

6. Omizzolo JAE. O princípio da integralidade na visita domiciliar. Um desafio do Programa Saúde da Família. http://www.tede.ufsc.br/teses/PNFRO 518.pdf (acessado em 02/Abr/2008).

7. Mattos RA. Os sentidos da integralidade: algumas reflexões acerca de valores que merecem ser definidos. In: Pinheiro R, Mattos RA, organizadores. Os sentidos da integralidade na atenção e no cuidado à saúde. Rio de Janeiro: Universidade do Estado do Rio de Janeiro; 2001. p. 39-64.

8. Mattos RA. A integralidade na prática (ou sobre a prática da integralidade). Cad Saúde Pública 2004; 20:1411-6. 
9. Pinheiro R. As práticas do cotidiano na relação oferta e demanda dos serviços de saúde: um campo de estudo e construção da integralidade. In: Pinheiro R, Mattos RA, organizadores. Os sentidos da integralidade na atenção e no cuidado à saúde. Rio de Janeiro: Universidade do Estado do Rio de Janeiro; 2001. p. 65-112.

10. Alves VS. Um modelo de educação em saúde para o Programa Saúde da Família: pela integralidade da atenção e reorientação do modelo assistencial. Interface Comun Saúde Educ 2005; 9:39-52.

11. Bosi MLM, Uchimura KY. Avaliação qualitativa de programas de saúde: Contribuições para propostas metodológicas centradas na integralidade e na humanização. In: Bosi MLM, Mercado-Martinez FJ, organizadores. Avaliação qualitativa de programas de saúde: enfoques emergentes. Petrópolis: Editora Vozes; 2006. p. 87-117.

12. Tesch R. Qualitative research: analysis, types \& softwares tools. New York: The Falmer Press; 1995.

13. Mercado FJ. O processo de análise qualitativa dos dados na investigação sobre serviços de saúde. In: Bosi MLM, Mercado-Martinez FJ, organizadores. Avaliação qualitativa de programas de saúde: enfoques emergentes. Petrópolis: Editora Vozes; 2006. p. 137-74.

14. Creswell JW. Qualitative inquiry and research design: choosing among five traditions: sage publications: international educational and professional publisher. London: Sage Publications; 1998.

15. Schwandt TA. Dictionary of qualitative inquiry. $3^{\text {rd }}$ Ed. Thousand Oaks: Sage Publications; 2007.

16. Willis JW. Foundations of qualitative research interpretive and critical approaches. London: Sage Publications; 2007.
17. Denzin NK, Lincoln YS. Handbook of qualitative research. London: Sage Publications; 1994.

18. Polit DF, Beck CT, Hungler BP. Compreensão do delineamento da pesquisa qualitativa. In: Polit DF, Beck CT, Hungler BP, organizadores. Fundamentos de pesquisa em enfermagem: métodos, avaliação, utilização. Porto Alegre: Artmed; 2004. p. 199-221.

19. Heidegger M. Ser e tempo. 2a Ed. Coleção Pensamento Humano. Petrópolis: Editora Vozes; 1990.

20. Hycner R. Relação e cura em gestalt-terapia. São Paulo: Summus; 1997.

21. Boff L. Saber cuidar: ética do humano, compaixão pela terra. Petrópolis: Editora Vozes; 2003.

22. Ortega JL, Infante C, Palacios ET. A duplicação de serviços como expressão de insatisfação dos pacientes. In: Bosi MLM, Mercado-Martinez FJ, organizadores. Pesquisa qualitativa de serviços de saúde. Petrópolis: Editora Vozes; 2004. p. 279-337.

23. Caetano R, Dain S. O Programa de Saúde da Família e a reestruturação da atenção básica à saúde nos grandes centros urbanos: velhos problemas, novos desafios. Physis (Rio J.) 2002; 12:11-21.

24. Campos FEC, Aguiar RAT, Oliveira VB. O desafio da expansão do Programa de Saúde da Família nas grandes capitais brasileiras. Physis (Rio J.) 2002; 12:47-58.

25. Favoreto CAO, Camargo Junior KR. Alguns desafios conceituais e técnico-operacionais para o desenvolvimento do Programa de Saúde da Família como uma proposta transformadora do modelo assistencial. Physis (Rio J.) 2002; 12:59-76.

Recebido em 12/Fev/2008

Versão final reapresentada em 15/Mai/2008 Aprovado em 14/Nov/2008 